\title{
Endovascular Management of Coarctation of the Aorta
}

\author{
D.R. Turner, M.R.C.P., F.R.C.R., B.Sc., ${ }^{1}$ and P.A. Gaines, F.R.C.P., F.R.C.R. ${ }^{1}$
}

Untreated thoracic aortic coarctation leads to early death predominantly because of hypertension and its cardiovascular sequelae. Surgical treatment has been available for $>50$ years and has improved hypertension and survival. More recently, endovascular techniques have offered a minimally invasive alternative to traditional open repair. Early and intermediate results suggest angioplasty and stenting have an important role in the management of aortic coarctation, particularly in adults and older children.

KEYWORDS: Coarctation, endovascular, angioplasty, stenting

Objectives: Upon completion of this article, the reader should have a better understanding of the role of endovascular therapy in coarctation management.

Accreditation: Tufts University School of Medicine (TUSM) is accredited by the Accreditation Council for Continuing Medical Education to provide continuing medical education for physicians.

Credit: TUSM designates this educational activity for a maximum of 1 AMA PRA Category 1 Credit $^{\mathrm{TM}}$. Physicians should only claim credit commensurate with the extent of their participation in the activity.

Coarctation of the aorta describes the congenital narrowing of any part of the descending thoracic or abdominal aorta. However, it typically refers to narrowing of the proximal thoracic aorta, at the level of the ductus or ligamentum arteriosum. Coarctation is the third most prevalent form of congenital heart disease, with an incidence of $\sim 20$ to 60 patients per 100,000 live births, ${ }^{1,2}$ accounting for 5 to $8 \%$ of all congenital heart defects.

There is a morphological spectrum of abnormalities, ranging from a discrete stenosis distal to the left subclavian artery to a hypoplastic aortic arch and isthmus that typically presents in infancy. Arch hypoplasia occurs in $\sim 25$ to $50 \%$ of cases. In some cases, coarctation is caused by a long tubular stenosis of the descending thoracic aorta. ${ }^{3}$ Thoracic aortic coarctation is frequently combined with other congenital defects, such as a bicuspid aortic valve, which occurs in some 20 to $85 \%$ of patients. ${ }^{4-6}$ Additional defects may further complicate the approach to patient management. ${ }^{6}$

Coarctation can be considered a primary (native) phenomenon, or a recurrent event, secondary to previous repair. Although there are many parallels in the management of native and recurrent coarctation, the pathophysiological processes responsible for secondary coarctation are different, and this may affect the approach and outcomes of management. Untreated coarctation causes morbidity and early demise by way of hypertension, congestive cardiac failure, myocardial infarction, stroke, aortic rupture, and infective endocarditis. The mean age at death is 33 to 35 years, and $90 \%$ of patients with untreated coarctation are dead by the 6 th decade. ${ }^{1,7}$

The treatment of coarctation has evolved since the first surgical repair by Crafoord in $1944 .{ }^{8}$ Open

\footnotetext{
${ }^{1}$ Sheffield Vascular Institute, Sheffield Teaching Hospitals NHS Foundation Trust, Northern General Hospital, Sheffield, United Kingdom.

Address for correspondence and reprint requests: D.R. Turner, M.R.C.P., F.R.C.R., B.Sc., Consultant Vascular Radiologist, Sheffield Vascular Institute, Sheffield Teaching Hospitals NHS Foundation Trust, Northern General Hospital, Herries Road, Sheffield S5 7AU,
}

United Kingdom.

Aorta and Great Vessels; Guest Editor, Tony Nicholson, B.Sc., M.Sc., M.B., Ch.B., F.R.C.R.

Semin Intervent Radiol 2007;24:153-166. Copyright (C) 2007 by Thieme Medical Publishers, Inc., 333 Seventh Avenue, New York, NY 10001, USA. Tel: +1(212) 584-4662.

DOI 10.1055/s-2007-980052. ISSN 0739-9529. 
operative techniques have provided the mainstay of intervention since that time, with gradual improvement in morbidity and mortality rates, such that with modern techniques, the results are generally excellent. ${ }^{9}$ However, a significant degree of morbidity and postoperative discomfort remains. Endovascular techniques offer a minimally invasive alternative to conventional open surgery and allow a shorter hospital stay. This form of therapy has quickly gained acceptance in many centers. However, the optimal form of management is controversial. Robust comparative data are lacking ${ }^{10}$ because direct comparisons of surgical versus endovascular therapy are limited. ${ }^{11-14}$ Comparison between studies is very difficult due to different patient populations and characteristics and the types of outcome associated with each approach. ${ }^{15}$ Moreover, techniques have evolved, and the longer-term data may reflect outmoded practice. Importantly, the only two randomized prospective studies reported to date were small and underpowered. ${ }^{12,16}$

The fact that surgical repair has evolved over 50 years, compared with approximately half that for angioplasty and even less for stenting, means that consistent long-term data for endovascular management are still lacking. Furthermore, the outcome data following repair suggest that coarctation is far from cured in a significant proportion of cases. Restenosis is a potential consequence of any type of repair, and late hypertension is relatively common, even in the absence of residual or recurrent coarctation. The challenge is to identify the place of these respective techniques in the management of (re)coarctation across the wide age range and variety of presentation.

\section{PATHOGENESIS OF NATIVE COARCTATION}

The exact mechanism of native coarctation is not entirely understood. Prenatal ultrasound abnormalities suggest that coarctation may already be present in utero. ${ }^{17}$ Abnormal fetal hemodynamics and antenatal constriction of ectopic ductal tissue have been implicated. ${ }^{18} \mathrm{It}$ was thought that upper limb hypertension developed because of the physical impedance created by the coarctation, with resultant cardiac strain a consequence of increased afterload. However, this view is too simplistic. Substantial evidence suggests that coarctation is part of a more widespread vascular condition. Medial degeneration, with increased collagen and reduced smooth muscle and elastin, has been noted in the aortic wall above and below the coarctation ${ }^{19,20}$ as early as 24 hours postpartum. ${ }^{19,21}$ Associated functional anomalies, including altered baroreceptor activity, reduced arterial reactivity and compliance, and increased arterial stiffness in the precoarctation vasculature, have also been noted. ${ }^{22,23} \mathrm{It}$ is likely that these changes contribute to the pathophysiology of hypertension, and that simply fixing the mechanical obstruction does not in itself reverse the structural and functional abnormalities in the proximal vasculature, resulting in the likelihood of late hypertension and its consequences. ${ }^{10,20,22,23}$

Moreover, large artery stiffness is known to accelerate hypertension, and in turn, hypertension leads to greater arterial stiffness. ${ }^{24}$ Exercise induced hypertension may reflect this inherent dysfunction of the upper segment vasculature known to occur in association with coarctation. ${ }^{16}$

\section{CLINICAL PRESENTATION}

Most cases of coarctation are diagnosed in children, with approximately a third presenting with critical coarctation in infancy. ${ }^{25}$ Severe stenosis is unmasked when the ductus arteriosus closes, causing cardiac failure due to the aortic obstruction. If the ductus remains patent, critical stenosis may remain undiagnosed. Less severe degrees of narrowing allow collaterals to become established around the coarctation, and may escape diagnosis until later in childhood. Approximately $20 \%$ of patients do not present until adulthood. ${ }^{26}$ The usual clinical picture of later presentation in children and adults is one of incidental hypertension. ${ }^{27,28}$ Occasionally, $\mathrm{pa}^{-}$ tients present with heart failure, aortic rupture or dissection, infective endocarditis, or stroke. ${ }^{29,30}$

\section{DIAGNOSIS}

Despite the advances in prenatal detection of congenital heart defects with fetal echocardiography, the diagnosis of coarctation in utero is notoriously difficult. ${ }^{17}$ If antenatal ultrasound is suggestive, careful postnatal followup with echocardiography is warranted. However, even with more rigorous prenatal screening, there is no evidence to indicate that the rates of diagnosis of coarctation in childhood are improving with time. ${ }^{2}$ Signs in infancy include features of cardiac failure and/or systolic murmur with discrepant arm-to-leg pulses or blood pressures. Clinical examination in children or adults may reveal radiofemoral delay and difference of blood pressure between the upper and lower limbs, in the presence or absence of arm hypertension. There may be palpable collateral vessels around the scapula and evidence of a systolic murmur in the axilla or back.

Routine investigations may give a clue to the diagnosis. Electrocardiography may be normal or show evidence of left ventricular strain or hypertrophy. Chest radiography may demonstrate an enlarged heart, abnormal cardiac contour, and in older children/adults, ascending aortic enlargement and rib notching, caused by collateral vessels. The diagnosis can be confirmed by several techniques. Transthoracic echocardiography is frequently the first line of investigation if coarctation is suspected, particularly in neonates and infants, because it 
avoids ionizing radiation and intravascular contrast agent and allows evaluation of the degree of coarctation, as well as other cardiac abnormalities. ${ }^{31-33}$ However, problems can be encountered in some patients, particularly adults, due to absence of a suitable acoustic window. ${ }^{31,34}$ Use of transesophageal echocardiography (TOE) may circumvent this issue, but TOE has its own limitations. ${ }^{34}$ Although use of echocardiographic gradients is widespread and has shown excellent correlation with catheter-measured gradients in neonates, ${ }^{35}$ there is still controversy regarding accuracy of Doppler ultrasound when compared with invasive monitoring. ${ }^{6,36-38}$ Arm-to-leg blood pressure difference by sphygmomanometry can provide an indirect estimate of the transcoarctation gradient ${ }^{32}$ but may not accurately quantify the stenosis. ${ }^{39}$

Recently, cross-sectional imaging techniques have been increasingly used, partly aided by increased availability of improving technology. Magnetic resonance imaging (MRI) has evolved to allow reproducible, detailed anatomical imaging, providing excellent correlation with conventional angiography. ${ }^{32,33,40}$ MRI offers several advantages over echocardiography, giving an overview of the relevant aortic morphology and anatomical relationships, including the presence of large collateral vessels. ${ }^{32,41}$ Velocity encoded cine MRI allows noninvasive quantification of the coarctation gradient, although this technique can be inaccurate, particularly in the presence of a very severe stenosis or a long diffuse coarctation segment. The degree of collateral flow may be a more reliable measure of severity ${ }^{31}$ especially if combined with anatomical data. ${ }^{42}$ However, MRI depends on the ability of the patient to lie motionless, and thus invariably general anesthesia is required if the technique is to be used in young children. Multidetector computed tomographic angiography (MDCTa) allows rapid acquisition and high-resolution imaging of the thoracic aorta and its branches, giving excellent anatomical information. However, the dependency on ionizing radiation and iodinated contrast medium, combined with the lack of functional detail, means its use may be limited in native coarctation.

The ability of catheter angiography to image the entire thoracic aorta and any large collateral vessels, in several projections, combined with the ability to measure the translesional gradient directly, meant it was generally considered the gold standard in evaluation of coarctation, particularly in older patients where the risks of ionizing radiation are less. ${ }^{42}$ More recently, it has allowed direct progression to endovascular therapy. However, the limitations of invasive catheter arteriography are well known, especially in younger patients, and its use as a diagnostic tool may become confined to those cases where doubt over the significance of a lesion detected by noninvasive imaging exists or where endovascular therapy is planned.

\section{What is Significant?}

In addition to clinical symptoms, several different factors have been suggested as indicative of significant coarctation or recoarctation, requiring treatment. In simplistic terms, a stenosis $>50 \%$ of the native vessel diameter is likely to have a hemodynamic effect, with a resultant pressure gradient across the lesion. However, a complex interplay exists among anatomical (e.g., effective flow orifice, geometry, length), mechanical (e.g., aortic compliance), flow rate, and ventricular variables (e.g., ventricular function and ventriculoarterial coupling). ${ }^{42}$ Although good correlation exists between differing imaging modalities in the anatomical assessment of stenosis severity, ${ }^{32}$ direct measurement may be impossible or inaccurate owing to anatomical factors, and thus indirect measures of stenosis severity are often utilized. The most commonly used is the translesional peak systolic gradient, and the most frequently cited value for a significant stenosis is a resting gradient $\geq 20 \mathrm{~mm}$ $\mathrm{Hg}{ }^{42-45}$ However, somewhat confusingly, numerous different definitions have been used. ${ }^{31,46,47}$

Current European Society of Cardiology (ESC) guidelines for "grown-up" congenital heart disease suggest intervention in those patients with resting- or exercise-induced hypertension and/or a gradient $\geq 30 \mathrm{~mm} \mathrm{Hg}{ }^{48}$ Gradients found only on exercise or by 24 -hour ambulatory blood pressure monitoring or the presence of left ventricular dysfunction are also considered to be indicators for treatment. ${ }^{45}$ Exercise-induced and ambulatory hypertension leads to an increased risk of adverse cardiovascular outcome, even if normotensive at rest. ${ }^{49,50}$ Whether these various parameters can be used interchangeably between different patient age ranges or native and recurrent coarctation is unknown, but this assumption is widespread throughout the literature.

\section{TREATMENT}

The timing of repair is an important determinant of outcome, particularly in the young. Early repair of native coarctation is associated with a lower risk of late hypertension $^{22,51,52}$ and improved survival, ${ }^{53}$ although the risk of recoarctation is higher. ${ }^{44,54,55}$ With later repair, the converse applies. Nevertheless, survival and hypertension are improved by surgical ${ }^{6,7,10,56,57}$ and endovascular treatment ${ }^{3,58-60}$ even in patients who present late in adulthood. ${ }^{61}$ Even in the absence of cure, medical management is frequently made easier, allowing a reduction in the burden of antihypertensive drugs. Factors to be considered when deciding the most appropriate form of management include age, aortic morphology, local institutional experience, and whether previous intervention has been performed. The presence of associated arch hypoplasia may cause a residual gradient following coarctation repair, particularly if severe or if presenting in later life, and it may be deemed necessary 
to treat at the same time. Compensatory growth may occur if the hypoplastic segment is moderately narrowed and the coarctation repaired in early life. ${ }^{62}$ In view of the complexities of coarctation management, particularly if combined with other congenital defects, some justifiably advocate a multidisciplinary approach. ${ }^{30}$ The improved survival of patients treated in childhood has meant a greater burden of follow-up and subsequent reintervention in later life.

\section{SURGICAL THERAPY}

Various types of operations are available to treat coarctation. ${ }^{63}$ These include excision with end-to-end anastomosis, excision with graft interposition, synthetic patch aortoplasty, subclavian flap angioplasty, and extra-anatomic bypass. No single technique has been proven to be better than another. Surgery may be preferred if coarctation is associated with other congenital cardiac defects, which can be addressed at the same time. Although repeat surgery for recoarctation or aneurysm formation is advocated by some, ${ }^{54,64}$ others report a relatively high operative risk. ${ }^{65,66}$

\section{Complications}

Initial surgical results demonstrated high perioperative mortality and morbidity, especially in neonates, but increased experience and refinement of technique has significantly reduced the reported adverse events, particularly in the last 10 to 15 years. ${ }^{5,9,44,67-70}$ Perioperative mortality rates in the largest published series to date revealed an overall mortality of $2.6 \%$, with the highest incidence of death occurring in patients $<1$ year old $(6.5 \%)$ and those $\geq 30$ years old $(4.5 \%){ }^{7}$

Aneurysm following coarctation repair can occur early or late. A variety of definitions makes comparison of incidence challenging between surgical and endovascular therapies. ${ }^{4,12,71-73}$ Reported incidence following open repair of native coarctation ranges from 0 to $46 \%$.,9,12,16,74-76 Suggested predisposing factors are late repair (>13.5 years), ${ }^{74}$ hypoplastic aortic arch, ${ }^{75}$ and synthetic patch graft repair, ${ }^{4,74,77}$ although the latter may depend on whether the coarctation ridge is resected. ${ }^{78,79}$ A dilated treated segment $>1.5$ times the diameter of the aorta at the level of the diaphragm has a high risk of progressive dilation, and regular follow-up imaging is recommended. ${ }^{4}$ Untreated postoperative aneurysms have a high risk of rupture and death, at an average of 7 to 15 years. $^{74,76}$ Surgical repair of postoperative aneurysms carries a relatively high mortality rate of $14 \%{ }^{80}$

Secondary hemorrhage may occur in $\sim 3$ to $4 \%$ of patients, ${ }^{81}$ and older patients are particularly at risk. ${ }^{30}$ Paraparesis may occur because of interruption of spinal blood flow during open repair, with an incidence of 0.3 to $2.4 \% ;{ }^{3,69,82}$ it is usually transient. ${ }^{69}$ Paradoxical hypertension has been widely reported following surgery ${ }^{69,83,84}$ and may occur in up to $76 \% .{ }^{69}$ Postcoartectomy syndrome is also reported to be relatively common in some surgical series. It is thought to relate to reperfusion of abdominal viscera. ${ }^{3}$

\section{ENDOVASCULAR THERAPY}

The first reported angioplasty of coarctation was in $1981{ }^{85}$ Its use was initially confined to cases of recoarctation, but this has subsequently expanded to involve native coarctation, with equivalent primary results. ${ }^{86}$ Angioplasty has been used in patients of every age range, and some longer term data are now available. .8,65,87-89 Initial reports suggested a high rate of complications, such as restenosis and aneurysm formation. However, there have been improvement in results with refinement of the technique, and this high rate may have been a result of balloon oversizing in earlier years. ${ }^{3}$

The first use of a stent for aortic coarctation was described in $1991 .^{90}$ The delivery of endovascular repair has been facilitated by improvements in technology, allowing smaller delivery systems and a wider range of devices. Stenting has been widely used in older children and adults, where devices can be deployed to (near) adult sizes and has become the procedure of choice in several centers. ${ }^{47,59,87,88}$ Stent placement has shown cost effectiveness when compared with surgery in this age group. ${ }^{91}$ The use of stents in young children is limited by the fact that typical devices still require an 8 to $12 \mathrm{~F}$ sheath, risking vascular damage, ${ }^{92}$ and perhaps more importantly, the fact that a stent "splints" the treated segment, leading to the prospect of "recoarctation" during somatic growth. Nevertheless, stent deployment even in younger children and neonates has been described, albeit in a palliative fashion. ${ }^{88,93}$ Future directions may lead to use of bioabsorbable stents in young children, ${ }^{94}$ which may theoretically solve some of the issues of stent use in this population.

Angioplasty causes a luminal gain by stretching and tearing the intimal layer of the coarctation segment, with variable extension into the media of the vessel wall. Choice of balloon size is important to try and prevent elastic recoil and maximize luminal gain without overly traumatizing what may already be a vulnerable vessel wall, because of medial degeneration. ${ }^{21}$ Particular caution is also recommended in patients $>50$ years of age, especially if the aorta is calcified, because degenerative disease may further weaken the arterial wall. ${ }^{95}$ Underdistension may cause residual stenosis, with a possible adverse long-term outcome. Overdistension could lead to aortic dissection, rupture, or aneurysm formation, and the healing response to vessel wall trauma may predispose to neointimal proliferation and subsequent restenosis. Use of a stent limits the amount of vessel wall 
trauma ${ }^{96}$ and its consequences by avoiding overdistension while minimizing elastic recoil and containing small dissections by the stent struts. ${ }^{97}$ Neointimal response may be greater in stenting rather than angioplasty, ${ }^{96}$ but this is likely to be offset by the greater initial luminal gain.

\section{TECHNIQUES OF ENDOVASCULAR REPAIR}

Endovascular repair is usually performed under general anesthesia or heavy sedation because coarctation dilatation can be extremely painful. An endovascular suite is optimal for imaging, and an experienced team is a necessity to minimize the potential risks of intervention in what can be a medically complicated set of patients. Transfemoral access is most commonly used, although other novel approaches are described for certain circumstances. ${ }^{98}$ A further contralateral transfemoral, transbrachial or transeptal (from the right heart) catheter may be placed to provide imaging from the proximal aorta during the procedure. Generally, angiography and translesional pressure gradients are measured before and following treatment. Additionally, a calibrated pigtail catheter can be used to measure the relevant aortic diameters if these have not been previously elucidated. The use of percutaneous closure devices has increased the practicality of the endovascular technique, and most patients can be discharged home from the hospital the following day; this contrasts with an average stay of 3.5 days post surgical repair. ${ }^{91}$

\section{Angioplasty}

Angioplasty is usually performed using a single balloon, but a kissing balloon technique has previously been used, allowing a reduction in vascular sheath size. ${ }^{87} \mathrm{~A}$ stiff guidewire is generally recommended to support the balloon catheter. There is little consensus on choice of balloon size in the literature, but most suggest it should be no greater than the diameter of the aorta at the diaphragm. ${ }^{65,66,84,87,89,99-101}$ Low-pressure inflation is usually sufficient to overcome any waist; should the waist fail to resolve and a significant pressure gradient remain, then a high pressure balloon may be used with caution. Alternatively, it may be decided to perform a staged redilation at a later date. Unfortunately, there is little science to determine the successful end point of coarctation angioplasty. The most frequently cited measure is a residual gradient $<20 \mathrm{~mm} \mathrm{Hg},{ }^{15,86,87,100}$ but European Society of Cardiology guidelines advocate a gradient $<30 \mathrm{~mm} \mathrm{Hg}$ as a success, ${ }^{48}$ and others indicate that a gradient $<10 \mathrm{~mm} \mathrm{Hg}$ is a better predictor of longerterm benefit and promote a more aggressive approach to management. ${ }^{73}$ Yet others suggest that providing there is no residual waist angiographically, a pressure gradient $>20 \mathrm{~mm} \mathrm{Hg}$ can be disregarded because vessel wall remodeling will ultimately provide a satisfactory outcome. ${ }^{101,102}$ Although no data suggest that gradient reduction below a particular level confers any additional long-term benefit, ${ }^{3}$ resting and exercise hypertension and increased left ventricular mass and impaired diastolic function have been observed in patients with low residual gradients. ${ }^{60}$ The question that remains to be answered is whether this is due to the residual gradient and will improve if the gradient is reduced, or whether documented changes in arterial reactivity and compliance in the precoarctation vasculature are responsible.

\section{Stenting}

Balloon-mounted stents such as Palmaz (Cordis, Miami Lakes, FL) or Cheatham Platinum (NuMed, Hopkinton, NY) devices are most often used because of their radial strength and accuracy of positioning. However, self-expanding devices have also been used, and they generally offer the advantage of greater flexibility and conformability. ${ }^{103}$ The stent size chosen should be appropriate to the intended final diameter and the length of the lesion (Fig. 1). Some advocate predilation, particularly if the coarctation is very severe, but this may lead to a higher risk of stent migration. ${ }^{104}$ Care should be exercised during stent deployment because the antegrade arterial pressure has a tendency to displace the stent assembly distally. Use of a balloonin-balloon delivery system may reduce the risk of migration during deployment. ${ }^{45,59}$ Placement of a long vascular sheath across the coarctation to protect the stent assembly while crossing the stenosis may also reduce the risk of malposition. Should stent migration occur, it is invariably displaced distally where it can usually be deployed safely in the distal aorta or iliac artery, but occasionally removal is warranted.

A balloon-size equivalent to the final intended diameter is usually chosen, although some propose that graded dilation is preferable, whereby initial underdilation (to $\sim 70$ to $80 \%$ of required diameter) opposes the stent to the aortic wall, and the indwelling stent can be further dilated with a larger balloon..$^{59,105}$ This enables a smaller delivery system. A variant of this technique is to perform the secondary dilation after a delay, to allow endothelialization and medial repair, with the aim of reducing the risk of rupture or aneurysm formation, ${ }^{106}$ and numerous studies suggest redilation to be safe, ${ }^{60,71,107-109}$ although serious complications can still arise. $^{110}$

Frequently, the juxtaductal anatomy is tortuous or there is poststenotic dilation or calcification, meaning the rigid balloon-expandable stent conforms poorly to the aortic contours, and the proximal and/or distal ends of the stent may not lie in apposition to the aortic wall. This can be observed in up to $72 \%$ of patients but does not seem to result in embolic or obstructive 

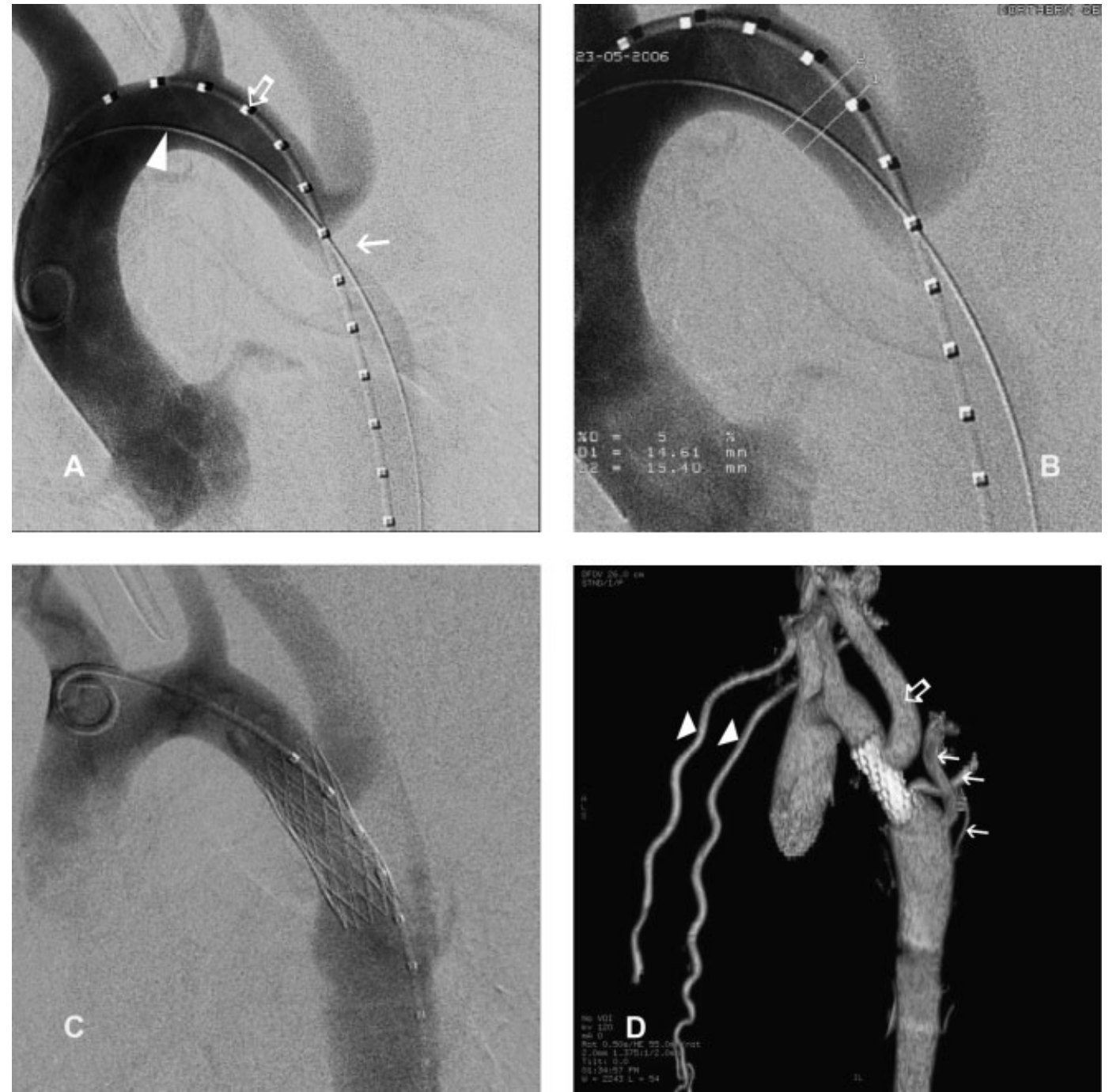

Figure 1 Native coarctation stent in young adult. (A) Coarctation (arrow) crossed with stiff guidewire (arrowhead) and calibrated pigtail catheter (open arrow) allowing (B) measurement of isthmus. (C) Successful stent placement. Note the coverage of the adjacent left subclavian artery origin. (D) Volume-rendered computed tomography reconstructions following coarctation stent. The stent covers the left subclavian artery origin (open arrow). Note the persistently enlarged intercostal (arrows) and internal thoracic (arrowheads) arteries.

consequences. ${ }^{111}$ However, some authors advocate flaring of the proximal and distal ends of the stent ${ }^{105}$ with the aim of promoting endothelialization. The risk with this strategy is that the free ends of the device, which can be rather sharp, may traumatize the wall, risking rupture, dissection, or aneurysm formation. ${ }^{3,71}$ The left subclavian origin is commonly adjacent to the coarctation; although covering branch vessel origins with stent struts theoretically predisposes to thromboembolic events, vessel narrowing, and branch occlusion, no apparent ill effects have been documented in the short term. ${ }^{95,111,112}$

Some groups endorse the use of stent grafts for the treatment of coarctation in certain circumstances, with the notion that the graft material may protect the vessel wall from dissection, aneurysm formation, and the consequences of rupture. ${ }^{59}$ However, there is little corroborative evidence that stent graft placement is any safer or more effective than uncovered stenting, and theoretically, stent graft use may make restenosis more likely because the supporting stent tends to exert less radial force. Furthermore, there is still no long-term data on the durability of modern stent grafts, a concern if considering placement in young patients. Use of stent grafts for complications of endovascular coarctation treatment in adults is justifiable because it parallels stent graft usage for other indications, such as degenerative aneurysms, dissection, and traumatic transection.

\section{ADJUNCTIVE TREATMENT}

Heparin should be given perioperatively in a dose of 50 to $100 \mathrm{U} / \mathrm{kg}$, and some advocate a heparin infusion for 48 hours afterward. ${ }^{106}$ The use of antiplatelet drugs is variable in the literature, although some recommend low-dose aspirin or clopidogrel for 6 months following 
stenting. ${ }^{59,113}$ Prostaglandin $\mathrm{E}_{1}$ may help alleviate the effects of severe coarctation in the newborn by reopening the ductus arteriosus. In older patients, appropriate control of blood pressure and minimizing other cardiovascular risk factors is warranted.

\section{OUTCOME OF ENDOVASCULAR THERAPY}

\section{Primary Success}

In the native subset (422 patients) studied in the Valvuloplasty and Angioplasty of Congenital Anomalies (VACA) registry, primary technical success was $81 \% .{ }^{86}$ However, most other reported series ( $>300$ patients in total) show primary success rates of $\geq 90 \%$ in children and adults. ${ }^{72,73,87,100,102,114}$ Predictors of poor initial outcome include nondiscrete lesions ${ }^{73,100,115}$ and lack of operator experience. ${ }^{86}$

The primary success of angioplasty for recurrent coarctation following surgery is reportedly 75 to 94\%. ${ }^{65,66,86,102}$ Walhout and colleagues found a better outcome in children with recoarctation than with adults; they postulated that greater scarring and less elasticity in the adult aortic wall was the cause for this discrepancy. ${ }^{102}$ Allied to this, in an earlier analysis of angioplasty for recoarctation in VACA, Hellenbrand et al found a better result when the angioplasty was performed early rather than late after discovery of the restenosis, possibly because of less scarring and fibrosis. ${ }^{116}$ The fact that primary success of angioplasty in native coarctation is better than for recoarctation may again reflect the more resistant nature of secondary stenosis to balloon treatment because of scar tissue. ${ }^{86}$

Stent placement for native coarctation demonstrates excellent primary results in $>95 \%$ of patients. ${ }^{3,73,88,104,105,109,117-119}$ The mean end gradient appears to be significantly better than with angioplasty alone, ${ }^{73,103,120}$ possibly by providing greater initial luminal gain ${ }^{87}$ and furthermore, stenting appears to be more effective in nondiscrete coarctation. ${ }^{73,121}$ Stenting of recurrent coarctation yields acute results equivalent to those for native stenosis. ${ }^{111}$

\section{Complications}

Very few deaths are described following angioplasty of native coarctation, with most series having no periprocedural mortality. In the VACA registry review of $1996,{ }^{86}$ a mortality rate of $0.7 \%$ was noted in children and adults. Mortality rates for angioplasty of recoarctation are equivalent to native lesions (0.7 to $1.1 \%){ }^{65,86}$ It was felt that scar formation following previous repair might render the recoarcted segment more resistant to rupture, aneurysm formation, and dissection than native coarctation. However, there was no significant difference in rupture rates in the VACA registry, ${ }^{86}$ although reported incidence of intimal flap/ tear was significantly greater in angioplasty of native coarctation.

There has been much debate regarding the incidence of aneurysms following native coarctation angioplasty, particularly in view of the histological findings of medial damage and the traumatic mechanism of action of angioplasty. Early reports of incidence as high as $50 \%$ were concerning, and a small randomized trial comparing angioplasty and surgery in children (3 to 10 years old) found a $20 \%$ and 30\% risk in short-term and long-term follow-up, respectively, after angioplasty, as opposed to $0 \%$ following operative repair. ${ }^{12,16}$ However, other studies suggests a much lower incidence of 0 to $7 \%{ }^{43,72,89,100,102,122}$ Interestingly, in contradistinction to postsurgical aneurysms, most aneurysms following angioplasty do not tend to progress on intermediate follow-up. ${ }^{12,43,100,123}$ Risk of aneurysm formation following angioplasty for recoarctation is reportedly $<7 \% .{ }^{65,101}$ Other significant complications of angioplasty in the VACA registry were rare: aortic rupture, $0.7 \%$; neurological event, $0.6 \%$; intimal tear/flap, 1.6\%; and vascular complications (pulse loss/thrombosis), $0.6 \% .^{86}$ These figures are in accordance with other series. ${ }^{65,124}$ Paradoxical hypertension and postcoarctectomy syndrome also appear to be uncommon. ${ }^{104}$

Deaths following stenting of native coarctation are rare. Underreporting may be partly the reason, but most papers report no periprocedural mortality. ${ }^{3,58,87,104,105,108,111,113}$ The true rate is likely to be $<2 \%$. ${ }^{59}$ The risk of aneurysm formation following stent implantation was reported as high as $17 \%$ in one study, ${ }^{111}$ but this may reflect the definition of aneurysm and the small number of patients in this series. Of 320 children and adults with native or recurrent coarctation, the risk of late aneurysm was found to be $4 \% .^{3}$ It is likely the risk is equivalent for native or recurrent coarctation stenting. Strut or complete stent fracture, particularly with certain types of device, is well recognized but usually does not lead to adverse outcome. ${ }^{125}$ Recurrent narrowing, although rare, is described in the context of transverse stent fracture, ${ }^{126}$ and there is a theoretical risk of mural trauma resulting in dissection, aneurysm, or perforation. ${ }^{59}$ Consequently, stent fracture may be considered for further intervention, either by placement of a further stent, or a stent graft, depending on the clinical scenario. Stent migration is a potential problem during implantation, due to stent slippage or balloon rupture. The risk of early migration is reportedly 0 to $12 \%$, with a mean of $\sim 5 \%$ from 227 cases. ${ }^{60,104-106,108,109,111,113}$ True late migration is thought to be extremely rare, although circumferential stent fracture may result in fragment distal embolization. ${ }^{59}$ 


\section{FOLLOW-UP}

Clinical review is indicated at 4 to 6 weeks postprocedure, and long-term follow up is required because of the risk of restenosis, late hypertension, and aneurysm formation. If the patient is found to be normotensive at first follow-up, some advocate a trial off antihypertensive medication. ${ }^{111}$ However, many recommend exercise or ambulatory blood pressure monitoring, despite questions regarding its predictive value and clinical relevance postcoarctation repair ${ }^{127,128}$ because hypertension is frequently found even if normotensive at rest. ${ }^{9,26,38,51,77,129-131}$ Although systolic parameters are the most frequently used in the literature, there is mounting evidence for diastolic dysfunction in coarctation, which is associated with left ventricular hypertrophy. ${ }^{50,60}$ It is known that stent placement reduces the increased end diastolic pressures and trend toward left ventricular hypertrophy. ${ }^{60}$ A lack of unanimity exists over which of these measures should be used to guide reintervention or antihypertensive treatment, and further evidence is needed.

Postprocedural imaging depends on local availability and expertise, and the limitations of each of these investigations are well known, particularly in young children. The indication for further imaging is not explicit, although most groups perform routine imaging at least early in follow-up to assess for complications. Recurrent hypertension, radiofemoral delay, onset of symptoms, or a changing chest radiograph may prompt further detailed examination in later follow-up. Most children, especially if young, are followed up using echocardiography, although postsurgical scarring or presence of a stent may interfere with interrogation, and the accuracy of gradient evaluation is even more questionable than in native disease. ${ }^{132,133}$ The preferred methods of follow-up imaging in older children and adults are MDCTa and MRI. ${ }^{63}$ These techniques can be used in conjunction with electrocardiographic gating to provide high levels of intracardiac and coronary artery detail. ${ }^{134}$ MRI, particularly fast or turbo spin echo and contrast-enhanced sequences, are advocated as the most clinically and cost-effective method of follow-up imaging, especially in adults following surgery or angioplasty. ${ }^{41,135-137}$ Unfortunately, the presence of an indwelling stent may cause susceptibility artifact, which may interfere with the diagnostic performance of MRI in this instance. MDCTa is particularly useful in this setting.

Catheter angiography as a method of initial follow-up imaging has largely fallen from favor, but it still has an important role to play in further assessment of possible restenosis, particularly because occasionally restenosis may take the form of a web that is difficult to see on static MR or CT angiography, although cine MRI may become a practical alternative in the future. ${ }^{63}$

\section{RECOARCTATION}

Recurrent stenosis may occur following any type of coarctation repair. In children, differential growth between the treated segment and the rest of the thoracic aorta may cause relative narrowing. Excessive neointimal proliferation, occurring at the site of surgical anastomosis or in response to vessel trauma during endovascular repair, may cause true restenosis, and this may be exacerbated following angioplasty by elastic recoil. ${ }^{109,138}$ However, the role of elastic recoil in the pathogenesis of recoarctation has been disputed. ${ }^{99}$ Significant recurrent coarctation is associated with late hypertension and increased mortality rate. ${ }^{53} \mathrm{~A}$ wide range of measurements has been proposed to define significant restenosis, reflecting the problems defining a significant primary lesion. The most widely used parameter, as with native disease, is a recurrent translesional gradient of $>20 \mathrm{~mm}$ $\mathrm{Hg}$, but a host of other definitions and indicators have been suggested. ${ }^{4,12,48,73,87,101,112,129,137,139}$ Treatment is generally advocated when there is evidence of hypertension, left ventricular hypertrophy or dilation, ${ }^{140}$ or in the presence of symptoms.

Reported rates of restenosis after surgical repair of native coarctation vary from 1.7 to $50 \%,{ }^{44,52-}$ $54,68,78,101,139-142$ but with modern techniques, the risk is probably $<10 \% .{ }^{67,141} \mathrm{~A}$ young age at repair tends to increase the risk of restenosis, particularly if during the neonatal period. ${ }^{78,83,141}$ Other implicated factors include arch hypoplasia ${ }^{78}$ and type of surgical repair. ${ }^{53,54} \mathrm{Re}-$ current stenosis following repeat surgery is said to have an incidence of 7 to $30 \%{ }^{82,143}$

Recoarctation following angioplasty of native coarctation has also been extensively documented. Very high rates of up to $83 \%$ are recorded in neonates, and this age group seems particularly susceptible. ${ }^{13,43,66,72,144}$ Angioplasty may still be useful as a palliative tool in this group. ${ }^{14,33,72}$ Rates of recurrent coarctation appear to decrease with age at intervention, ${ }^{43}$ especially if the stenosis is discrete, and recent results cite an incidence of 0 to $15 \%$ in adults. ${ }^{58,73,89,102,145}$ The use of angioplasty in recurrent coarctation appears to yield much better results, even in the very young, ${ }^{142}$ particularly if the lesion is discrete,${ }^{65}$ and is viewed by many as the optimal management in this circumstance, ${ }^{97,101,142}$ because the risks of repeat surgery are generally greater than the initial intervention.

The risk of recoarctation following stenting appears lower than angioplasty, ${ }^{60,87,105,106,108,109,111,113}$ possibly because elastic recoil is minimized by the supporting stent struts. ${ }^{109,138}$ Mild intimal hyperplasia is a common and expected finding following stent placement, but any tendency toward restenosis is offset by the greater initial luminal gain compared with angioplasty. Furthermore, stenting can successfully alleviate hypoplastic segments, which are also known to predict 

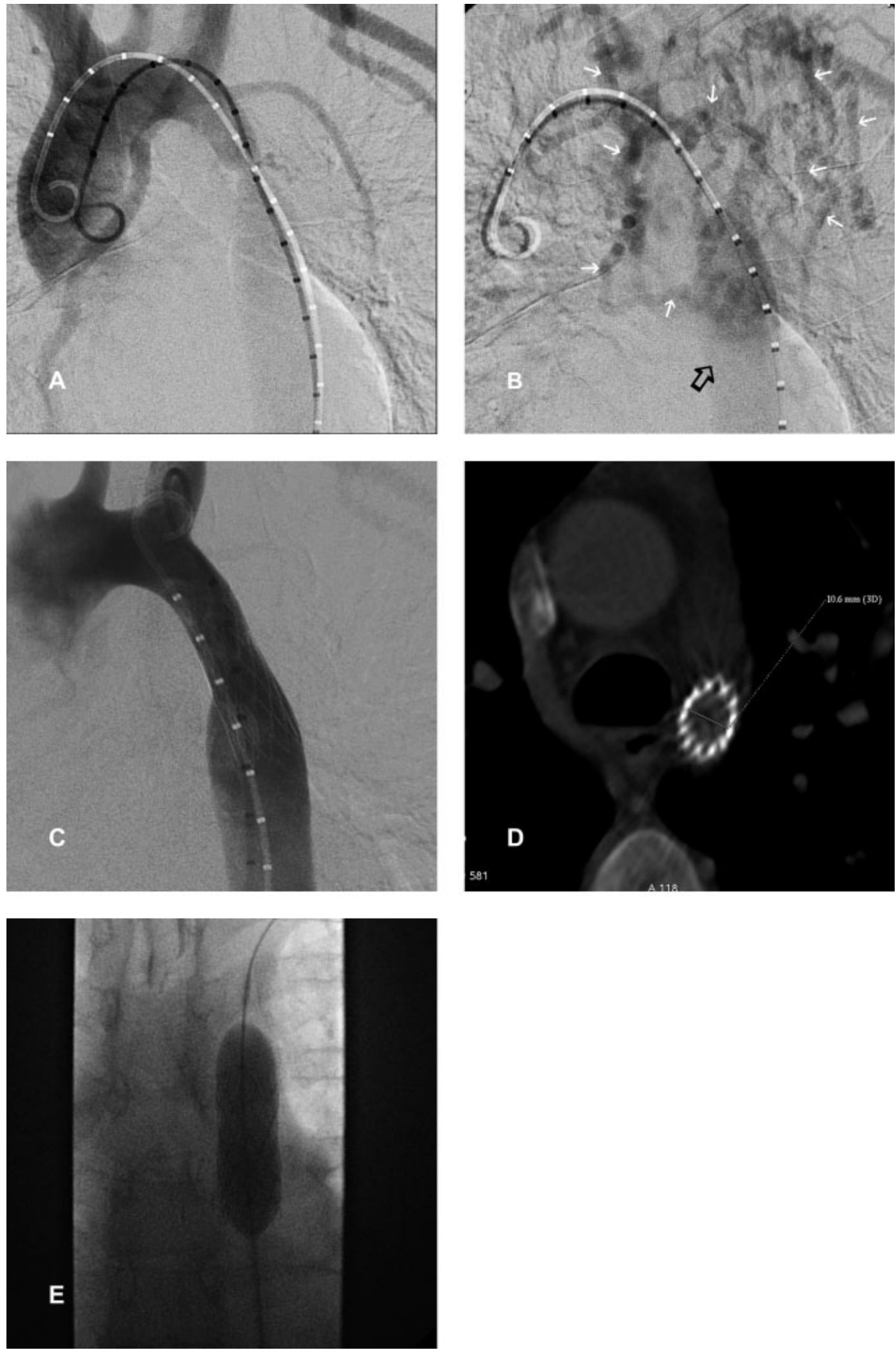

Figure 2 Redilation. (A) Severe native coarctation with (B) extensive collateralization (white arrows) on late angiographic phase, filling aorta distal to stenosis (black open arrow). (C) Successful stent placement, dilated to $15 \mathrm{~mm}$. (D) Persistent hypertension and radiofemoral delay. The stent diameter had reduced to $11 \mathrm{~mm}$ in the midportion on computed tomography, presumably because of elastic recoil. (E) Repeat dilation to $15 \mathrm{~mm}$ provided gradient relief and clinical improvement. 
recoarctation following angioplasty. ${ }^{73,105,109}$ However, comparison is difficult at present, owing to small published numbers, disparate results, and lack of long-term data. ${ }^{87}$ Most stenting series have dealt with adolescents or adults because of the previously noted problems of using stents in the very young. Restenosis requiring reintervention, following stenting for native and recurrent coarctation in 177 pooled patients, occurs in $\sim 5 \%$ at intermediate followup; ${ }^{71,105,108,109,113}$ no significant difference is reported in restenosis following treatment of native versus recurrent coarctation. ${ }^{11}$ Stent redilation has been successfully performed following recoarctation (Fig. 2) and to compensate for somatic growth in children. $60,71,87,92,106,109$

\section{HYPERTENSION}

Hypertension is perhaps the most important outcome measure following coarctation repair. There is a direct correlation between the degree of systolic hypertension and the risk of premature death. ${ }^{7}$ The reported prevalence of late hypertension depends on the diagnostic criteria and duration of follow-up and may be detected in 7 to $75 \%$ of patients following surgical repair; ${ }^{4,7,130}$ as many as $45 \%$ have no evidence of recurrent stenosis. ${ }^{26}$ Numerous studies have found the risk of developing late hypertension is reduced with earlier surgical repair, ${ }^{7,26,44,139,146}$ and this trend is true even in adults, ${ }^{147}$ leading to improved long-term survival. ${ }^{7,53}$ Nevertheless, even in those operated on in infancy with no evidence of recoarctation, high blood pressure ( $>95$ th percentile) is found in as many as $21 \%$ of patients, 10 to 12 years later. $^{51}$ The optimal age of repair in asymptomatic children with coarctation is reportedly 1.5 years because the interplay of perioperative risk, late hypertension, and recurrent coarctation are at their lowest, ${ }^{7,52,146}$ although with modern surgical techniques, this age may shift even lower. ${ }^{52}$ Perhaps not surprisingly, the risk of hypertension increases with the interval since operation, ${ }^{44,51,129}$ and 30 to 40 years after surgery, only 32 to $34 \%$ are expected to be normotensive. ${ }^{44,53}$

The prevalence after endovascular repair is more obscure, partly because of the relative infancy of the technique. Furthermore, most stenting series have been described in the adolescent or adult population, where hypertension is often already entrenched. Early improvement in hypertension may occur in $95 \%$ following stent. ${ }^{103}$ However, hypertension is known to persist in up to a third of adult patients following treatment. ${ }^{114}$ In the intermediate term, $\sim 50$ to $75 \%$ of patients will be able to discontinue pharmacotherapy or at least benefit from an improvement in blood pressure control, possibly allowing a reduction in their medica- tion. ${ }^{58,73,87,89,102,109,113,114,145,148}$ The outcome of later follow-up is awaited.

\section{CONCLUSION}

The endovascular management of coarctation is evolving. At present, there is a limited role for angioplasty in the palliation of severe coarctation in young children, due to the high risk of later recoarctation, although it has a useful place in the treatment of recurrent coarctation. Endovascular techniques are a safe and effective treatment in older children and adults; stent placement may be particularly advantageous in nondiscrete coarctation, and appears to result in low rates of recoarctation. Cure or amelioration of preexisting hypertension can be expected, but the long-term outcome is presently unknown. It is likely that results will mirror those noted following successful surgery, and life expectancy will improve but not normalize.

\section{REFERENCES}

1. Campbell M. Natural history of coarctation of the aorta. Br Heart J 1970;32:633-640

2. Hoffman JI, Kaplan S. The incidence of congenital heart disease. J Am Coll Cardiol 2002;39:1890-1900

3. Mullen MJ. Coarctation of the aorta in adults: do we need surgeons? Heart 2003;89:3-5

4. Jenkins NP, Ward C. Coarctation of the aorta: natural history and outcome after surgical treatment. QJM 1999;92: 365-371

5. Warnes CA. Bicuspid aortic valve and coarctation: two villains part of a diffuse problem. Heart 2003;89:965-966

6. Marx GR. "Repaired" aortic coarctation in adults: not a "simple" congenital heart defect. J Am Coll Cardiol 2000; 35:1003-1006

7. Cohen M, Fuster V, Steele PM, Driscoll D, McGoon DC. Coarctation of the aorta: long-term follow-up and prediction of outcome after surgical correction. Circulation 1989;80:840-845

8. Radegran K. The early history of cardiac surgery in Stockholm. J Card Surg 2003;18:564-572

9. Carr JA. The results of catheter-based therapy compared with surgical repair of adult aortic coarctation. J Am Coll Cardiol 2006;47:1101-1107

10. Daniels SR. Repair of coarctation of the aorta and hypertension: does age matter? Lancet 2001;358:89

11. Walhout RJ, Lekkerkerker JC, Oron GH, Bennink GB, Meijboom EJ. Comparison of surgical repair with balloon angioplasty for native coarctation in patients from 3 months to 16 years of age. Eur J Cardiothorac Surg 2004;25:722727

12. Shaddy RE, Boucek MM, Sturtevant JE, et al. Comparison of angioplasty and surgery for unoperated coarctation of the aorta. Circulation 1993;87:793-799

13. Johnson MC, Canter CE, Strauss AW, Spray TL. Repair of coarctation of the aorta in infancy: comparison of surgical and balloon angioplasty. Am Heart J 1993;125:464-468

14. Rao PS, Chopra PS, Koscik R, Smith PA, Wilson AD. Surgical versus balloon therapy for aortic coarctation in 
infants $<$ or $=3$ months old. J Am Coll Cardiol 1994;23: 1479-1483

15. Hanley FL. The various therapeutic approaches to aortic coarctation: is it fair to compare? J Am Coll Cardiol 1996;27:471-472

16. Cowley CG, Orsmond GS, Feola P, McQuillan L, Shaddy RE. Long-term, randomized comparison of balloon angioplasty and surgery for native coarctation of the aorta in childhood. Circulation 2005;111:3453-3456

17. Head CE, Jowett VC, Sharland GK, Simpson JM. Timing of presentation and postnatal outcome of infants suspected of having coarctation of the aorta during fetal life. Heart 2005;91:1070-1074

18. Liberman L, Gersony WM, Flynn PA, Lamberti JJ, Cooper RS, Stare TJ. Effectiveness of prostaglandin E1 in relieving obstruction in coarctation of the aorta without opening the ductus arteriosus. Pediatr Cardiol 2004;25:49-52

19. Niwa K, Perloff JK, Bhuta SM, et al. Structural abnormalities of great arterial walls in congenital heart disease: light and electron microscopic analyses. Circulation 2001;103: 393-400

20. Sehested J, Baandrup U, Mikkelsen E. Different reactivity and structure of the prestenotic and poststenotic aorta in human coarctation: implications for baroreceptor function. Circulation 1982;65:1060-1065

21. Isner JM, Donaldson RF, Fulton D, Bhan I, Payne DD, Cleveland RJ. Cystic medial necrosis in coarctation of the aorta: a potential factor contributing to adverse consequences observed after percutaneous balloon angioplasty of coarctation sites. Circulation 1987;75:689-695

22. de Divitiis M, Pilla C, Kattenhorn M, et al. Vascular dysfunction after repair of coarctation of the aorta: impact of early surgery. Circulation 2001;104(suppl 1):I165I170

23. Gardiner HM, Celermajer DS, Sorensen KE, et al. Arterial reactivity is significantly impaired in normotensive young adults after successful repair of aortic coarctation in childhood. Circulation 1994;89:1745-1750

24. Franklin SS, Gustin WT, Wong ND, et al. Hemodynamic patterns of age-related changes in blood pressure. The Framingham Heart Study. Circulation 1997;96:308-315

25. Hoffman JI, Kaplan S, Liberthson RR. Prevalence of congenital heart disease. Am Heart J 2004;147:425-439

26. de Divitiis M, Rubba P, Calabro R. Arterial hypertension and cardiovascular prognosis after successful repair of aortic coarctation: a clinical model for the study of vascular function. Nutr Metab Cardiovasc Dis 2005;15:382-394

27. Ward KE, Pryor RW, Matson JR, Razook JD, Thompson WM, Elkins RC. Delayed detection of coarctation in infancy: implications for timing of newborn follow-up. Pediatrics 1990;86:972-976

28. Ing FF, Starc TJ, Griffiths SP, Gersony WM. Early diagnosis of coarctation of the aorta in children: a continuing dilemma. Pediatrics 1996;98:378-382

29. Rhodes AB, O'Donnell SD, Gillespie DL, et al. The endovascular management of recurrent aortic hypoplasia and coarctation in a 15-year-old male. J Vasc Surg 2005;41:531534

30. Ramnarine I. Role of surgery in the management of the adult patient with coarctation of the aorta. Postgrad Med J 2005;81:243-247

31. Sechtem U. Imaging of aortic coarctation: difficult choices. Eur Heart J 1995;16:1315-1316
32. Mendelsohn AM, Banerjee A, Donnelly LF, Schwartz DC. Is echocardiography or magnetic resonance imaging superior for precoarctation angioplasty evaluation? Cathet Cardiovasc Diagn 1997;42:26-30

33. McCrindle BW. Coarctation of the aorta. Curr Opin Cardiol 1999;14:448-452

34. Engvall J, Sjoqvist L, Nylander E, Thuomas KA, Wranne B. Biplane transoesophageal echocardiography, transthoracic Doppler, and magnetic resonance imaging in the assessment of coarctation of the aorta. Eur Heart J 1995; 16:1399-1409

35. Marx GR, Allen HD. Accuracy and pitfalls of Doppler evaluation of the pressure gradient in aortic coarctation. J Am Coll Cardiol 1986;7:1379-1385

36. Rao PS, Carey P. Doppler ultrasound in the prediction of pressure gradients across aortic coarctation. Am Heart J 1989;118:299-307

37. Lim DS, Ralston MA. Echocardiographic indices of Doppler flow patterns compared with MRI or angiographic measurements to detect significant coarctation of the aorta. Echocardiography 2002;19:55-60

38. Carvalho JS, Redington AN, Shinebourne EA, Rigby ML, Gibson D. Continuous wave Doppler echocardiography and coarctation of the aorta: gradients and flow patterns in the assessment of severity. Br Heart J 1990;64: 133-137

39. Araoz PA, Reddy GP, Tarnoff H, Roge CL, Higgins CB. MR findings of collateral circulation are more accurate measures of hemodynamic significance than arm-leg blood pressure gradient after repair of coarctation of the aorta. J Magn Reson Imaging 2003;17:177-183

40. Godart F, Labrot G, Devos P, McFadden E, Rey C, Beregi JP. Coarctation of the aorta: comparison of aortic dimensions between conventional MR imaging, 3D MR angiography, and conventional angiography. Eur Radiol 2002;12: 2034-2039

41. Didier D, Saint-Martin C, Lapierre C, et al. Coarctation of the aorta: pre and postoperative evaluation with MRI and MR angiography: correlation with echocardiography and surgery. Int J Cardiovasc Imaging 2006;22:457-475

42. Nielsen JC, Powell AJ, Gauvreau K, Marcus EN, Prakash A, Geva T. Magnetic resonance imaging predictors of coarctation severity. Circulation 2005;111:622-628

43. Rao PS, Galal O, Smith PA, Wilson AD. Five- to nine-year follow-up results of balloon angioplasty of native aortic coarctation in infants and children. J Am Coll Cardiol 1996; 27:462-470

44. Toro-Salazar OH, Steinberger J, Thomas W, Rocchini AP, Carpenter B, Moller JH. Long-term follow-up of patients after coarctation of the aorta repair. Am J Cardiol 2002; 89:541-547

45. Piechaud JF. Stent implantation for coarctation in adults. J Interv Cardiol 2003;16:413-418

46. Waldman JD, Karp RB. How should we treat coarctation of the aorta? Circulation 1993;87:1043-1045

47. Eicken A, Pensl U, Sebening W, et al. The fate of systemic blood pressure in patients after effectively stented coarctation. Eur Heart J 2006;27:1100-1105

48. Deanfield J, Thaulow E, Warnes C, et al. Management of grown up congenital heart disease. Eur Heart J 2003;24: 1035-1084

49. Allison TG, Cordeiro MA, Miller TD, Daida H, Squires RW, Gau GT. Prognostic significance of exercise-induced 
systemic hypertension in healthy subjects. Am J Cardiol 1999;83:371-375

50. Singh JP, Larson MG, Manolio TA, et al. Blood pressure response during treadmill testing as a risk factor for newonset hypertension. The Framingham Heart Study. Circulation 1999;99:1831-1836

51. O'Sullivan JJ, Derrick G, Darnell R. Prevalence of hypertension in children after early repair of coarctation of the aorta: a cohort study using casual and 24 hour blood pressure measurement. Heart 2002;88:163-166

52. Seirafi PA, Warner KG, Geggel RL, Payne DD, Cleveland RJ. Repair of coarctation of the aorta during infancy minimizes the risk of late hypertension. Ann Thorac Surg 1998;66:1378-1382

53. Presbitero $\mathrm{P}$, Demarie D, Villani M, et al. Long term results (15-30 years) of surgical repair of aortic coarctation. $\mathrm{Br}$ Heart J 1987;57:462-467

54. Dodge-Khatami A, Backer CL, Mavroudis C. Risk factors for recoarctation and results of reoperation: a 40-year review. J Card Surg 2000;15:369-377

55. McElhinney DB, Yang SG, Hogarty AN, et al. Recurrent arch obstruction after repair of isolated coarctation of the aorta in neonates and young infants: is low weight a risk factor? J Thorac Cardiovasc Surg 2001;122:883-890

56. Wells WJ, Prendergast TW, Berdjis F, et al. Repair of coarctation of the aorta in adults: the fate of systolic hypertension. Ann Thorac Surg 1996;61:1168-1171

57. Ozyazicioglu A, Ates A, Yekeler I, Balci AY, Bozkurt E. Repair of coarctation of the aorta in adults and hypertension. Cardiovasc Surg 2003;11:353-357

58. Fawzy ME, Awad M, Hassan W, Al Kadhi Y, Shoukri M, Fadley F. Long-term outcome (up to 15 years) of balloon angioplasty of discrete native coarctation of the aorta in adolescents and adults. J Am Coll Cardiol 2004;43:1062-1067

59. Pilla CB, Fontes VF, Pedra CA. Endovascular stenting for aortic coarctation. Expert Rev Cardiovasc Ther 2005;3:879890

60. Marshall AC, Perry SB, Keane JF, Lock JE. Early results and medium-term follow-up of stent implantation for mild residual or recurrent aortic coarctation. Am Heart J 2000; 139:1054-1060

61. Bauer M, Alexi-Meskishvili VV, Bauer U, Alfaouri D, Lange PE, Hetzer R. Benefits of surgical repair of coarctation of the aorta in patients older than 50 years. Ann Thorac Surg 2001;72:2060-2064

62. Siewers RD, Ettedgui J, Pahl E, Tallman T, del Nido PJ. Coarctation and hypoplasia of the aortic arch: will the arch grow? Ann Thorac Surg 1991;52:608-613: discussion 613614

63. Shih MC, Tholpady A, Kramer CM, Sydnor MK, Hagspiel KD. Surgical and endovascular repair of aortic coarctation: normal findings and appearance of complications on CT angiography and MR angiography. AJR Am J Roentgenol 2006;187:W302-W312

64. Sakopoulos AG, Hahn TL, Turrentine M, Brown JW. Recurrent aortic coarctation: is surgical repair still the gold standard? J Thorac Cardiovasc Surg 1998;116:560-565

65. Yetman AT, Nykanen D, McCrindle BW, et al. Balloon angioplasty of recurrent coarctation: a 12-year review. J Am Coll Cardiol 1997;30:811-816

66. Maheshwari S, Bruckheimer E, Fahey JT, Hellenbrand WE. Balloon angioplasty of postsurgical recoarctation in infants: the risk of restenosis and long-term follow-up. J Am Coll Cardiol 2000;35:209-213

67. Gibbs JL. Treatment options for coarctation of the aorta. Heart 2000;84:11-13

68. Bacha EA, Almodovar M, Wessel DL, et al. Surgery for coarctation of the aorta in infants weighing less than $2 \mathrm{~kg}$. Ann Thorac Surg 2001;71:1260-1264

69. Bhat MA, Neelakandhan KS, Unnikrishnan M, Rathore RS, Mohan Singh MP, Lone GN. Fate of hypertension after repair of coarctation of the aorta in adults. Br J Surg 2001;88:536-538

70. Backer CL. Coarctation: the search for the Holy Grail. J Thorac Cardiovasc Surg 2003;126:329-331

71. Chessa M, Carrozza M, Butera G, et al. Results and midlong-term follow-up of stent implantation for native and recurrent coarctation of the aorta. Eur Heart J 2005;26: 2728-2732

72. Fletcher SE, Nihill MR, Grifka RG, O'Laughlin MP, Mullins CE. Balloon angioplasty of native coarctation of the aorta: midterm follow-up and prognostic factors. J Am Coll Cardiol 1995;25:730-734

73. Zabal C, Attie F, Rosas M, Buendia-Hernandez A, GarciaMontes JA. The adult patient with native coarctation of the aorta: balloon angioplasty or primary stenting? Heart 2003; 89:77-83

74. von Kodolitsch Y, Aydin MA, Koschyk DH, et al. Predictors of aneurysmal formation after surgical correction of aortic coarctation. J Am Coll Cardiol 2002;39:617-624

75. Bogaert J, Gewillig M, Rademakers F, et al. Transverse arch hypoplasia predisposes to aneurysm formation at the repair site after patch angioplasty for coarctation of the aorta. J Am Coll Cardiol 1995;26:521-527

76. Knyshov GV, Sitar LL, Glagola MD, Atamanyuk MY. Aortic aneurysms at the site of the repair of coarctation of the aorta: a review of 48 patients. Ann Thorac Surg 1996; 61:935-939

77. Celermajer DS, Greaves K. Survivors of coarctation repair: fixed but not cured. Heart 2002;88:113-114

78. Walhout RJ, Lekkerkerker JC, Oron GH, Hitchcock FJ, Meijboom EJ, Bennink GB. Comparison of polytetrafluoroethylene patch aortoplasty and end-to-end anastomosis for coarctation of the aorta. J Thorac Cardiovasc Surg 2003; 126:521-528

79. Backer CL, Paape K, Zales VR, Weigel TJ, Mavroudis C. Coarctation of the aorta: repair with polytetrafluoroethylene patch aortoplasty. Circulation 1995;92(suppl): II132-II136

80. Ince $H$, Petzsch $M$, Rehders $T$, et al. Percutaneous endovascular repair of aneurysm after previous coarctation surgery. Circulation 2003;108:2967-2970

81. Preventza O, Wheatley GH III, Williams J, et al. Endovascular approaches for complex forms of recurrent aortic coarctation. J Endovasc Ther 2006;13:400-405

82. Ralph-Edwards AC, Williams WG, Coles JC, Rebeyka IM, Trusler GA, Freedom RM. Reoperation for recurrent aortic coarctation. Ann Thorac Surg 1995;60:1303-1307

83. Koller M, Rothlin M, Senning A. Coarctation of the aorta-review of 362 operated patients: long-term follow-up and assessment of prognostic variables. Eur Heart J 1987;8: 670-679

84. Choy M, Rocchini AP, Beekman RH, et al. Paradoxical hypertension after repair of coarctation of the aorta in 
children: balloon angioplasty versus surgical repair. Circulation 1987;75:1186-1191

85. Singer MI, Rowen M, Dorsey TJ. Transluminal aortic balloon angioplasty for coarctation of the aorta in the newborn. Am Heart J 1982;103:131-132

86. McCrindle BW, Jones TK, Morrow WR, et al. Acute results of balloon angioplasty of native coarctation versus recurrent aortic obstruction are equivalent. Valvuloplasty and Angioplasty of Congenital Anomalies (VACA) Registry Investigators. J Am Coll Cardiol 1996;28:18101817

87. Macdonald S, Thomas SM, Cleveland TJ, Gaines PA. Angioplasty or stenting in adult coarctation of the aorta? A retrospective single center analysis over a decade. Cardiovasc Intervent Radiol 2003;26:357-364

88. Suarez de Lezo J, Pan M, Romero M, et al. Percutaneous interventions on severe coarctation of the aorta: a 21-year experience. Pediatr Cardiol 2005;26:176-189

89. Paddon AJ, Nicholson AA, Ettles DF, Travis SJ, Dyet JF. Long-term follow-up of percutaneous balloon angioplasty in adult aortic coarctation. Cardiovasc Intervent Radiol 2000;23:364-367

90. O'Laughlin MP, Perry SB, Lock JE, Mullins CE. Use of endovascular stents in congenital heart disease. Circulation 1991;83:1923-1939

91. George JC, Shim D, Bucuvalas JC, et al. Cost-effectiveness of coarctation repair strategies: endovascular stenting versus surgery. Pediatr Cardiol 2003;24:544-547

92. Sanders SP. Endovascular stent treatment of aortic coarctation. Am Heart J 2000;139:936-938

93. Lee ML. Endovascular stent for the aortic coarctation in a $1.7-\mathrm{kg}$ premie presenting intractable heart failure. Int J Cardiol 2006;113:236-238

94. Schranz D, Zartner P, Michel-Behnke I, Akinturk H. Bioabsorbable metal stents for percutaneous treatment of critical recoarctation of the aorta in a newborn. Catheter Cardiovasc Interv 2006;67:671-673

95. Mahadevan V, Mullen MJ. Endovascular management of aortic coarctation. Int J Cardiol 2004;97(suppl 1):75-78

96. Ohkubo M, Takahashi $\mathrm{K}$, Kishiro $\mathrm{M}$, Akimoto $\mathrm{K}$, Yamashiro Y. Histological findings after angioplasty using conventional balloon, radiofrequency thermal balloon, and stent for experimental aortic coarctation. Pediatr Int 2004; 46:39-47

97. Rosenthal E. Stent implantation for aortic coarctation: the treatment of choice in adults? J Am Coll Cardiol 2001;38: 1524-1527

98. Rao PS, Wilson AD, Brazy J. Transumbilical balloon coarctation angioplasty in neonates with critical aortic coarctation. Am Heart J 1992;124:1622-1624

99. Rao PS, Waterman B. Relation of biophysical response of coarcted aortic segment to balloon dilatation with development of recoarctation following balloon angioplasty of native coarctation. Heart 1998;79:407-411

100. Ovaert C, McCrindle BW, Nykanen D, MacDonald C, Freedom RM, Benson LN. Balloon angioplasty of native coarctation: clinical outcomes and predictors of success. J Am Coll Cardiol 2000;35:988-996

101. Siblini G, Rao PS, Nouri S, Ferdman B, Jureidini SB, Wilson AD. Long-term follow-up results of balloon angioplasty of postoperative aortic recoarctation. Am J Cardiol 1998;81:61-67
102. Walhout RJ, Lekkerkerker JC, Ernst SM, Hutter PA, Plokker TH, Meijboom EJ. Angioplasty for coarctation in different aged patients. Am Heart J 2002;144:180-186

103. Tyagi S, Singh S, Mukhopadhyay S, Kaul UA. Self- and balloon-expandable stent implantation for severe native coarctation of aorta in adults. Am Heart J 2003;146:920 928

104. Ledesma M, Alva C, Gomez FD, et al. Results of stenting for aortic coarctation. Am J Cardiol 2001;88:460-462

105. Hamdan MA, Maheshwari S, Fahey JT, Hellenbrand WE. Endovascular stents for coarctation of the aorta: initial results and intermediate-term follow-up. J Am Coll Cardiol 2001;38:1518-1523

106. Magee AG, Brzezinska-Rajszys G, Qureshi SA, et al. Stent implantation for aortic coarctation and recoarctation. Heart 1999;82:600-606

107. Duke C, Rosenthal E, Qureshi SA. The efficacy and safety of stent redilatation in congenital heart disease. Heart 2003; 89:905-912

108. Suarez de Lezo J, Pan M, Romero M, et al. Immediate and follow-up findings after stent treatment for severe coarctation of aorta. Am J Cardiol 1999;83:400-406

109. Ebeid MR, Prieto LR, Latson LA. Use of balloonexpandable stents for coarctation of the aorta: initial results and intermediate-term follow-up. J Am Coll Cardiol 1997; 30:1847-1852

110. Fejzic Z, van Oort A. Fatal dissection of the descending aorta after implantation of a stent in a 19-year-old female with Turner's syndrome. Cardiol Young 2005;15:529-531

111. Harrison DA, McLaughlin PR, Lazzam C, Connelly M, Benson LN. Endovascular stents in the management of coarctation of the aorta in the adolescent and adult: one year follow up. Heart 2001;85:561-566

112. Boshoff D, Budts W, Mertens L, et al. Stenting of hypoplastic aortic segments with mild pressure gradients and arterial hypertension. Heart 2006;92:1661-1666

113. Thanopoulos BD, Hadjinikolaou L, Konstadopoulou GN, Tsaousis GS, Triposkiadis F, Spirou P. Stent treatment for coarctation of the aorta: intermediate term follow up and technical considerations. Heart 2000;84:65-70

114. deGiovanni JV, Lip GY, Osman K, et al. Percutaneous balloon dilatation of aortic coarctation in adults. Am J Cardiol 1996;77:435-439

115. Tyagi S, Arora R, Kaul UA, Sethi KK, Gambhir DS, Khalilullah M. Balloon angioplasty of native coarctation of the aorta in adolescents and young adults. Am Heart J 1992; 123:674-680

116. Hellenbrand WE, Allen HD, Golinko RJ, Hagler DJ, Lutin W, Kan J. Balloon angioplasty for aortic recoarctation: results of Valvuloplasty and Angioplasty of Congenital Anomalies Registry. Am J Cardiol 1990;65:793-797

117. Golden $\mathrm{AB}$, Hellenbrand WE. Coarctation of the aorta: stenting in children and adults. Catheter Cardiovasc Interv 2007;69:289-299

118. Mahadevan VS, Vondermuhll IF, Mullen MJ. Endovascular aortic coarctation stenting in adolescents and adults: angiographic and hemodynamic outcomes. Catheter Cardiovasc Interv 2006;67:268-275

119. Shah L, Hijazi Z, Sandhu S, Joseph A, Cao QL. Use of endovascular stents for the treatment of coarctation of the aorta in children and adults: immediate and midterm results. J Invasive Cardiol 2005;17:614-618 
120. Pedra CA, Fontes VF, Esteves CA, et al. Stenting vs. balloon angioplasty for discrete unoperated coarctation of the aorta in adolescents and adults. Catheter Cardiovasc Interv 2005;64:495-506

121. Hornung TS, Benson LN, McLaughlin PR. Interventions for aortic coarctation. Cardiol Rev 2002;10:139-148

122. Tynan M, Finley JP, Fontes V, Hess J, Kan J. Balloon angioplasty for the treatment of native coarctation: results of Valvuloplasty and Angioplasty of Congenital Anomalies Registry. Am J Cardiol 1990;65:790-792

123. Robles P, Olmedilla P, Jimenez JJ. Aneurysm formation following stent implantation for aortic coarctation detected by multidetector computed cardiac tomography. Eur Heart J 2006;27:2774

124. Ussia GP, Marasini M, Pongiglione G. Paraplegia following percutaneous balloon angioplasty of aortic coarctation: a case report. Catheter Cardiovasc Interv 2001;54:510-513

125. Ledesma M, Jauregui R, Ceron CK, et al. Stent fracture after stent therapy for aortic coarctation. J Invasive Cardiol 2003;15:719-721

126. Carrozza M, Santoro G, Giovanna Russo M, Caianiello G, Calabro R. Stress stent fracture: is stent angioplasty really a safe therapeutic option in native aortic coarctation? Int J Cardiol 2006;113:127-128

127. Swan L, Goyal S, Hsia C, Hechter S, Webb G, Gatzoulis MA. Exercise systolic blood pressures are of questionable value in the assessment of the adult with a previous coarctation repair. Heart 2003;89:189-192

128. Benbassat J, Froom P. Blood pressure response to exercise as a predictor of hypertension. Arch Intern Med 1986;146: 2053-2055

129. Vriend JW, Mulder BJ. Late complications in patients after repair of aortic coarctation: implications for management. Int J Cardiol 2005;101:399-406

130. Johnson D, Perrault H, Vobecky SJ, Fournier A, Davignon A. Influence of the postoperative period and surgical procedure on ambulatory blood pressure-determination of hypertension load after successful surgical repair of coarctation of the aorta. Eur Heart J 1998;19:638-646

131. Sigurdardottir LY, Helgason H. Exercise-induced hypertension after corrective surgery for coarctation of the aorta. Pediatr Cardiol 1996;17:301-307

132. Hauser M. Exercise blood pressure in congenital heart disease and in patients after coarctation repair. Heart 2003; 89:125-126

133. De Mey S, Segers P, Coomans I, Verhaaren H, Verdonck P. Limitations of Doppler echocardiography for the postoperative evaluation of aortic coarctation. J Biomech 2001; 34:951-960

134. Baum U, Anders K, Ropers D, et al. Multi-slice spiral CT imaging after surgical treatment of aortic coarctation. Eur Radiol 2005;15:353-355

135. Therrien J, Thorne SA, Wright A, Kilner PJ, Somerville J. Repaired coarctation: a "cost-effective" approach to iden- tify complications in adults. J Am Coll Cardiol 2000;35: 997-1002

136. Vriend JW, Oosterhof T, Mulder B. Noninvasive imaging for the postoperative assessment of aortic coarctation patients. Chest 2005;127:2295

137. Bogaert J, Kuzo R, Dymarkowski S, et al. Follow-up of patients with previous treatment for coarctation of the thoracic aorta: comparison between contrast-enhanced MR angiography and fast spin-echo MR imaging. Eur Radiol 2000;10:1847-1854

138. Ino T, Ohkubo M. Dilation mechanism, causes of restenosis and stenting in balloon coarctation angioplasty. Acta Paediatr 1997;86:367-371

139. Pearl JM, Manning PB, Franklin C, Beekman R, Cripe L. Risk of recoarctation should not be a deciding factor in the timing of coarctation repair. Am J Cardiol 2004;93:803805

140. Zoghbi J, Serraf A, Mohammadi S, et al. Is surgical intervention still indicated in recurrent aortic arch obstruction? J Thorac Cardiovasc Surg 2004;127:203-212

141. Younoszai AK, Reddy VM, Hanley FL, Brook MM. Intermediate term follow-up of the end-to-side aortic anastomosis for coarctation of the aorta. Ann Thorac Surg 2002;74:1631-1634

142. Fiore AC, Fischer LK, Schwartz T, et al. Comparison of angioplasty and surgery for neonatal aortic coarctation. Ann Thorac Surg 2005;80:1659-1664; discussion 16641655

143. Sweeney MS, Walker WE, Duncan JM, Hallman GL, Livesay JJ, Cooley DA. Reoperation for aortic coarctation: techniques, results, and indications for various approaches. Ann Thorac Surg 1985;40:46-49

144. Park Y, Lucas VW, Sklansky MS, Kashani IA, Rothman A. Balloon angioplasty of native aortic coarctation in infants 3 months of age and younger. Am Heart J 1997;134:917923

145. Hassan W, Malik S, Akhras N, Amri MA, Shoukri M, Fawzy ME. Long-term results (up to 18 years) of balloon angioplasty on systemic hypertension in adolescent and adult patients with coarctation of the aorta. Clin Cardiol 2007;30:75-80

146. Brouwer RM, Erasmus ME, Ebels T, Eijgelaar A. Influence of age on survival, late hypertension, and recoarctation in elective aortic coarctation repair: including long-term results after elective aortic coarctation repair with a follow-up from 25 to 44 years. J Thorac Cardiovasc Surg 1994;108:525-531

147. Ozkokeli M, Gunduz H, Sensoz Y, et al. Blood pressure changes after aortic coarctation surgery performed in adulthood. J Card Surg 2005;20:319-321

148. Bulbul ZR, Bruckheimer E, Love JC, Fahey JT, Hellenbrand WE. Implantation of balloon-expandable stents for coarctation of the aorta: implantation data and short-term results. Cathet Cardiovasc Diagn 1996;39:36-42 